\title{
Construyendo Interculturalidad: Pueblos Indígenas, Educación y Políticas de Identidad en América Latina
}

\section{Juliana Ströbele-Gregor, Olaf Kaltmeier y Cornelia Giebeler (comp)}

GTZ Programa Fortalecimiento de Organizaciones Indígenas en América Latina, Eschborn, 2010, 49 págs.

\section{Antonio Elizalde Hevia*}

Recibido 25.02.2010

Aceptado 17.03.2010

$* * *$

Este libro, resultado de un esfuerzo compartido por diversas instituciones, investigadores y editores, encabezados por el Grupo de Investigación E Pluribus Unum? Ethnic Identities in Transnational Integration Processes in the Americas de la Universidad de Bielefeld, trata un tema central para el futuro de nuestras mestizas sociedades latinoamericanas: la necesaria construcción -en el presente que vivimos- de la interculturalidad en nuestra América Latina. Esto en el nuevo contexto donde los pueblos indígenas se han comenzado a transformar en actores indispensables en el ámbito político, hecho está ocurriendo especialmente en las sociedades andinas donde se produjo una ruptura en la "larga duración colonial”.

Es en este contexto de transnacionalización que la diseminación de diversas políticas de identidades aparece como el tópico de este Grupo de Investigación conducido por Sebastian Thies, Josef Raab y Olaf Kaltmeier en el Center for Interdisciplinary Research (ZiF) de la Universidad de Bielefeld. Con el fin de establecer un diálogo interdisciplinario sobre este tema, han desarrollado el concepto de "campo de políticas de identidad", basado por una parte en la teoría de campo de Pierre Bourdieu y por otra en enfoques constructivistas y otros relacionados con el reciente complexity turn en los estudios sociales. También aquí se originó la idea de asumir las políticas educativas y las traducciones entre el campo de las políticas de identidad y el campo educativo.

*Universidad Bolivariana, Santiago, Chile. Email: aelizalde@ubolivariana.cl 
Cabe señalar que en este camino hacia la interculturalidad, Ecuador, y más aún Bolivia, han vivido una ruptura muchísimo más profunda que los otros países, debido a los masivos procesos organizativos que experimentan. En Chile en tanto, el movimiento mapuche se ve confrontado con una estrategia de criminalización masiva por parte del Estado. En Colombia, el reconocimiento étnico formal establecido en las normas constitucionales queda en entredicho por la violencia (para- militar) real. En Perú, se aprecia un tardío proceso organizativo indígena y un aprovechamiento de varios líderes políticos mestizos -desde Alejandro Toledo hasta Ollanta Humala- que hacen uso de la etnicidad como recurso simbólico para alcanzar sus metas electorales.

Durante los años noventa predominaron en América Latina diversas iniciativas en torno al reconocimiento cultural y político de los pueblos indígenas entre los que se incluyen los referidos al idioma y a la educación. En la actualidad es posible apreciar, en especial en Bolivia y en Ecuador, procesos políticos que van más allá de la educación intercultural bilingüe impulsada hacia fines del siglo recién pasado. Este libro explora la importancia y el impacto de la Educación Intercultural Bilingüe (EIB) en función del reconocimiento de la pluralidad étnica y la multiculturalidad -reivindicación propia del movimiento indígena desde hace muchos años- en las sociedades latinoamericanas con presencia de pueblos indígenas. Debido a la presión de las organizaciones indígenas, particularmente durante la década de los noventa, los gobiernos de varios países - principalmente Bolivia, Perú, Ecuador y Guatemala- se vieron obligados a realizar reformas educativas e implementar la EIB y, por medio de ello, incluir la cultura y los idiomas indígenas en el sistema educativo. En otros países de Latinoamérica se desarrollaron otras formas de integración de las culturas en la educación.

En este contexto, aunque subsiste la cooperación internacional a nivel técnico y financiero, las organizaciones socio-políticas indígenas han tenido un papel importante durante el proceso de desarrollo y ejecución de estas reformas educativas. Ello se ve favorecido porque la EIB está inseparablemente vinculada con políticas de identidad, las que se expresan desde los niveles macro políticos de los Estados-naciones y de los organismos internacionales, hasta los niveles micro sociales de la constitución del sujeto en relación con el otro.

En particular, se ha buscado explorar los conceptos de interculturalidad que sostienen los diferentes actores directa o indirectamente y relacionados con los Programas de la EIB, siendo ellos principalmente las organizaciones indígenas, los padres de familia, el Estado y la cooperación internacional. También se han recogido los objetivos de cada uno de los actores en relación a las reformas educativas. Por otro lado se han analizado los enfoques pedagógicos y lingüísticos de la EIB, detectando los logros, desafíos, y obstáculos, se han discutido los grados de coherencia existente entre el discurso político sobre la construcción de una sociedad democrática, con su componente de diversidad cultural, y su expre- 
sión real en las políticas educativas, lingüísticas y culturales del Estado. También se ha rescatado la aceptación o el rechazo a ella por parte de los padres de familia y de otros segmentos de la sociedad.

En la primera sección del libro se discute la relevancia social y política de la Educación Intercultural Bilingue. Olaf Kaltmeier en su artículo titulado "Educación intercultural, políticas de identidad y ciudadanía" explora las interrelaciones entre EIB y las políticas de identidad. Juliana Strobele-Gregor a su vez en "Educación Intercultural Bilingüe en América Latina $-\dot{¿}$ Una contribución a la construcción de una sociedad democrática incluyente?” discute el aporte y los límites de la EIB como enfoque para fomentar una ciudadanía multicultural y pluriétnica.

En la segunda sección se enfoca, desde perspectivas poscoloniales, el concepto de la interculturalidad. Cornelia Giebeler en "Conceptos de Inter-, Trans -, e Intraculturalidad en la Educación” discute estos conceptos en las publicaciones de autores latinoamericanos-, elucidando su aporte a este debate. Menciona algunas reflexiones sobre el diálogo teórico de los términos y el aporte que hacen al debate sobre la Educación. Por su parte Sarah Corona y Rebeca Pérez en su texto "Cinco desaciertos de la educación intercultural y una estrategia indígena” ponen de relieve los errores cometidos en la educación intercultural y ofrecen la visión de una propuesta indígena.

En la tercera sección, se exploran diferentes prácticas de la educación intercultural bilingüe en diversos ámbitos regionales. Teresa Valiente en su artículo titulado "Educación Intercultural Bilingüe en Latinoamérica. Visión y realidad de un proceso en la región andina” discute la brecha entre visión y realidad de la práctica de la EIB. Utta von Gleich a su vez en "La Diplomatura de Revitalización Lingüística y Cultural: La Universidad Indígena Intercultural (UII) y la Subred de Revitalización Lingüística” presenta esta propuesta formativa como un instrumento de la educación intercultural en función de la revitalización de lenguas amenazadas en America Latina.

En la cuarta seccion, se presentan diversas propuestas y perspectivas para las políticas educativas en el Siglo XXI. En los casos de Ecuador y Bolivia, los gobiernos de Rafael Correa y de Evo Morales han realizado transformaciones en el campo de las políticas de identidad, las cuales se expresan en diferentes propuestas en búsqueda de superar la EIB de las últimas decadas. Anita Krainer en el texto titulado "La educación intercultural en Ecuador: logros, desafíos y situación actual” describe el desarrollo de la educación intercultural en Ecuador y analiza los logros y desafíos, enfocando la situación actual con el gobierno de Rafael Correa. Walter Gutierrez en su artículo "Descolonizar la educación: Los nuevos ejes de la interculturalidad y la participación social en el Estado plurinacional de Bolivia” explica los cambios en la Educación Intercultural Bilingue bajo el gobierno de Evo Morales, y pone de relieve que urge una descolonización de la educación. 
Este libro resulta un aporte de notable interés para todos los educadores latinoamericanos comprometidos en procesos educativos con las mayorías indígenas invisibilizadas durante siglos en nuestro continente. Ellos mediante su resistencia más que centenaria han logrado preservar saberes imprescindibles de recuperar y de asumir como epistemes fundantes para nueva cultura, en la cual la relación de aceptación plena, hospitalaria y cordial con lo otro, con lo diferente, con la Pachamama sea la base de sustentación que haga posible un sumak kawsay para todos los latinoamericanos. 